\title{
Efeitos do incremento da fibra em detergente neutro na dieta de suínos sobre a morfologia dos órgãos digestivos e não digestivos
}

Jacinta Diva Ferrugem GOMES ${ }^{1}$

Romualdo Shigueo

FUKUSHIMA ${ }^{2}$

Soraia Marques PUTRINO ${ }^{1}$

Carlos GROSSKLAUS ${ }^{3}$

Gustavo Júlio Melo Monteiro de LIMA $^{4}$

Correspondência para:

JACINTA DIVA FERRUGEM GOMES

Departamento de Zootecnia

Faculdade de Zootecnia e Engenharia de

Alimentos

Universidade de São Paulo

Av. Duque de Caxias Norte, 225

13635-900-Pirassununga-SP

jacintaf@usp.br

Recebido para publicação: 02/08/2004 Aprovado para publicação: 23/08/2005

\author{
1- Departamento de Zootecnia da Faculdade de Zootecnia e Engenharia de \\ Alimentos da Universidade de São Paulo, Pirassununga - SP \\ 2 - Departamento de Nutrição e Produção Animal da Faculdade de \\ Medicina Veterinária e Zootecnia da Universidade de São Paulo, \\ Pirassununga - SP \\ 3 - Socil Guyomarc'H \\ 4 - Centro Nacional de Pesquisa em Suínos e Aves, CNPSA/EMBRAPA-SC
}

\section{Resumo}

Objetivou-se avaliar os efeitos da inclusão na ração de 0 ou $8 \%$ de fibra em detergente neutro proveniente de feno de gramínea sobre a morfologia dos órgãos digestivos e não digestivos de suínos nas fases de creche e de crescimento-terminação. Foram utilizados suínos mestiços alimentados à vontade com rações isoprotéicas e isoenergéticas, em experimento inteiramente casualizado. Ao final de cada período, os animais foram abatidos e eviscerados. Observou-se que a ração fibrosa promoveu, na creche, aumento do peso do estômago vazio, do intestino grosso e do ceco cheio (expressos em percentual do peso vivo dos animais). Nos animais da fase de crescimento-terminação, registrou-se aumento do peso do trato gastrointestinal cheio e do estômago vazio. $\mathrm{O}$ aumento do peso de alguns órgãos digestivos sugere possível adaptação morfológica à presença de ração fibrosa.

\section{Introdução}

A utilização de forragens e outros volumosos, como fonte de fibra dietética na alimentação de suínos, não representa um conceito novo, pois já era teorizado por Carroll há mais de sessenta anos atrás (CARROLL, 1936, apud POLLMANN; DANIELSON; PEO JR ${ }^{1}$ ). Embora os animais não-ruminantes, como os suínos, digiram e utilizem a fração fibrosa dos alimentos de forma diversa dos ruminantes, a fibra dietética vem sendo considerada uma fonte alternativa de energia na alimentação desta espécie animal, principalmente para animais destinados ao abate nas fases de crescimento-terminação e de pósterminação (185 dias e $135 \mathrm{~kg}$ de peso vivo), bem como para animais destinados para a reprodução. A utilização de alimentos fibrosos objetiva o bem estar dos suínos ${ }^{2,3,4}$, controlar o excessivo ganho de peso advindo de maior deposição de tecido adiposo e minimizar o estresse decorrente do confinamento e da restrição alimentar de fêmeas reprodutoras ${ }^{5,6}$.

É importante ressaltar que cerca de 5 a 30\% do requerimento de energia de manutenção, pode ser suprido através da utilização dos ácidos graxos voláteis de cadeia curta, resultantes da fermentação da fibra dietética no intestino grosso ${ }^{7}$. Segundo alguns pesquisadores ${ }^{8,9,10}$, o aumento do teor de ácidos graxos voláteis no intestino grosso, em decorrência da fermentação da fibra dietética da ração: 1) contribui para o metabolismo energético dos suínos, especialmente para animais adultos; 2) atua na proliferação celular do epitélio intestinal com significativo aumento da produção de 
muco protetor; 3) altera a motilidade intestinal; 4) estimula a liberação do muco intestinal; 5) eleva o fluxo sangüíneo do colo e 6) eleva a taxa de renovação celular do epitélio.

Os componentes da fração fibrosa dos alimentos não são digeridos pelas enzimas tissulares do organismo animal e, quando presentes no trato intestinal, podem afetar diretamente as características físicas do conteúdo intestinal, e conseqüentemente, a própria morfologia e histologia dos órgãos envolvidos no processo digestivo ${ }^{11,12}$. Consequentemente, tais estudos podem fornecer dados relevantes para uma estratégia alimentar e direcionar adequadamente a produção suinícola, que além de se confrontar com a crescente competição com a alimentação humana por grãos ${ }^{13,14}$, também esbarra na limitada capacidade do trato digestivo desta espécie animal, em processar material fibroso.

A grande maioria dos autores empregou teores relativamente altos de fibra na ração de suínos. Considerandose a limitada capacidade do trato digestivo, mas ainda desejando-se auferir os possíveis efeitos benéficos advindos da utilização de fibra na ração, é que se propôs e a presente pesquisa, objetivando avaliar os efeitos de níveis moderados de adição de fibra em detergente neutro (FDN) na ração, de 0 ou $8 \%$, sobre o peso de órgãos digestivos e não digestivos.

\section{Materiais e Métodos}

A pesquisa foi conduzida no Setor de Suinocultura do Campus de Pirassununga, Universidade de São Paulo, Pirassununga, SP.

Para o experimento da fase de creche, foram utilizados 26 leitões (fêmeas e machos castrados) mestiços (Large White Landrace), com idade inicial de 42 dias com $28,1 \mathrm{~kg}$ e idade final de 73 dias e $28,1 \mathrm{~kg}$, respectivamente, alojados em 2 baias $\left(2,13 \mathrm{~m}^{2} /\right.$ animal) coletivas equipadas com bebedouro tipo chupeta e comedouro semi-automático. Água e ração foram fornecidos ad libitum, durante todo o período experimental (30 dias). O desmame dos animais foi realizado aos 21 dias de idade, de forma abrupta, ou seja, não gradual.

Para o experimento envolvendo as fases de crescimento e terminação, foram utilizados 24 suínos (fêmeas e machos castrados), mestiços (Large White ' Landrace), com idades inicial e final de 74 e 146 dias e pesos inicial e final de 25,0 e $88,3 \mathrm{~kg}$, respectivamente. Os animais foram alojados em gaiolas individuais (medindo $1,8 \mathrm{~m}^{2}$ ), equipadas com bebedouro tipo chupeta e comedouro semi-automático. Água e ração foram fornecidos ad libitum, durante todo o período experimental (72 dias). Estas gaiolas ficaram localizadas em um galpão aberto com área de $140 \mathrm{~m}^{2}$, coberto com telhas de barro e pé direito de 3,5 metros.

Os suínos receberam, durante todo o período, rações isonutritivas, isoenergéticas e isoprotéicas (Tabela 1), formuladas de acordo com as tabelas de exigências nutricionais constantes no $\mathrm{NRC}^{15}$. A fonte de fibra dietética, na forma de FDN, foi proveniente do feno de Tifton (Cynodon dactylon), o qual foi finamente moído e adicionado à ração farelada, determinando dois níveis de FDN: grupo suplementado com FDN e grupo controle. Os teores de FDN no feno de Tifton foram determinados seguindo o procedimento laboratorial descrito por Goering e Van Soest ${ }^{16}$. As demais análises laboratoriais seguiram as rotinas descritas em $\mathrm{AOAC}^{17}$.

Antes do abate, os suínos passaram por jejum hídrico e alimentar de 16 horas. Após o tradicional sacrifício dos animais, a cavidade abdominal de cada suíno foi aberta por incisão longitudinal, e pesados os órgãos digestivos cheios (trato gastrointestinal total, estômago, intestino delgado, intestino grosso, ceco e colo), os órgãos digestivos vazios (estômago, ceco 
e colo) e os não digestivos (pâncreas, fígado, vesícula biliar, baço, rins, pulmões e coração).

O delineamento experimental empregado foi o de blocos inteiramente casualizados, com dois tratamentos (grupo controle e grupo suplementado com $8 \%$ de FDN), sendo 13 repetições para o experimento da creche e 12 repetições para o experimento do crescimentoterminação. A análise de variância foi realizada através do procedimento "General Linear Model" do SAS ${ }^{18}$. As médias dos pesos dos órgãos foram comparadas pelo teste de Tukey $(P<0,05$; $P<0,01)$.

\section{Resultados e Discussão}

As alterações provocadas pelo aumento do consumo de fibra dietética são observadas diretamente sobre o trato gastrointestinal (TGI) de suínos ${ }^{19}$, sendo que as dietas ricas neste componente dietético são responsáveis por modificações nos processos de ingestão e digestão dos diversos nutrientes. Dentre as propriedades da fibra dietética incluemse: capacidade de retenção de água, volume, viscosidade, adsorção e ligação com outros compostos nutricionais ${ }^{20}$.

O oferecimento de $8 \%$ adicional de FDN na ração de leitões em creche, resultou em aumento nos pesos (porcentagem do peso vivo) do estômago vazio, do intestino grosso e do ceco cheio (Tabela 2). Já para os animais que receberam ração com maior nível de fibra em detergente neutro, ao final da fase de terminação, foi observado maior peso apenas para o TGI e estômago vazio (Tabela 3). Os demais parâmetros mostraram-se inalterados.

Pekas, Yen e Pond ${ }^{21}$ encontraram além de aumento do peso do TGI, também maior peso do intestino delgado, colo, coração e rins de suínos em terminação alimentados com $50 \%$ de feno de alfafa. Em pesquisa posterior, Gomes ${ }^{13}$ observou aumento linear do peso do estômago vazio e do coração de suínos em pré-puberdade e puberdade, recebendo crescentes níveis de FDN na ração. Pond, Jung e Varel ${ }^{22}$ relataram que os pesos relativos do fígado, coração, estômago vazio, intestinos delgado e grosso aumentaram quando se ofereceu ração contendo elevado nível de fibra (43\% de FDN, obtido pela inclusão de $80 \%$ de farinha de alfafa). Maiores pesos do estômago, cheio e vazio, de suínos em terminação alimentados com altos teores de FDN foram observados por Huo ${ }^{11}$. Estes dados sugerem, de acordo com Sakata ${ }^{9}$, uma adaptação morfológica dos órgãos, ainda que parcial, ao componente fibra dietética.

Algumas fontes fibrosas, que não são totalmente digeridas pelas enzimas do TGI, podem afetar diretamente as características físicas do conteúdo intestinal, e conse-qüentemente a própria morfologia dos órgãos envolvidos no processo digestivo. Cassidy et al. ${ }^{11}$ e Jin et al. ${ }^{12}$ afirmaram que dietas contendo fibra dietética são responsáveis por alterações na morfologia intestinal de animais nãoruminantes. Entretanto, o papel dos diversos fatores dietéticos sobre o crescimento e desen-volvimento intestinal destes animais ainda não é completamente conhecido $^{12}$.

O maior volume do conteúdo intestinal resulta em maior expansão do material volumoso, uma vez que o aumento do volume do conteúdo do intestino delgado está relacionado à capacidade de retenção de água bem como maior viscosidade da fração fibra dietética. Esta situação conduz a um esvaziamento gastrointestinal mais lento e conseqüente aumento do volume dos órgãos digestivos ${ }^{20}$.

Pode-se observar que o declínio na eficiência alimentar observado em suínos alimentados com dietas contendo elevados teores de fibra dietética, deve-se primordialmente à barreira física imposta pela 
Tabela 1-Composição percentual das rações experimentais oferecidas aos suínos durante as fases de creche, crescimento e terminação

\begin{tabular}{|c|c|c|c|c|c|c|}
\hline \multirow{4}{*}{ Ingredientes } & \multicolumn{6}{|c|}{ Fases } \\
\hline & \multicolumn{2}{|c|}{ Creche } & \multicolumn{2}{|c|}{ Crescimento } & \multicolumn{2}{|c|}{ Terminação } \\
\hline & \multicolumn{2}{|c|}{ FDN, \% } & \multicolumn{2}{|c|}{ FDN, \% } & \multicolumn{2}{|c|}{ FDN, $\%$} \\
\hline & 0 & 8 & 0 & 8 & 0 & 8 \\
\hline Milho & 67,53 & 57,00 & 80,83 & 65,93 & 86,26 & 72,14 \\
\hline Farelo de soja & 24,86 & 24,95 & 16,00 & 17,44 & 10,70 & 11,89 \\
\hline Feno moído & - & 10,00 & - & 10,00 & - & 10,00 \\
\hline Açúcar & 3,90 & 3,00 & - & - & - & - \\
\hline Gordura & 0,40 & 1,80 & - & - & - & - \\
\hline Óleo & - & - & - & 3,71 & - & 3,45 \\
\hline Fosfato bicálcico & 2,40 & 2,31 & 1,82 & 1,80 & 1,38 & 1,35 \\
\hline Calcário calcítito & - & - & 0,21 & 0,15 & 0,27 & 0,22 \\
\hline Caulim & - & - & 0,16 & - & 0,44 & - \\
\hline Sal & 0,30 & 0,30 & 0,30 & 0,30 & 0,30 & 0,30 \\
\hline Suplemento micromineral & $0,10^{\mathrm{a}}$ & $0,10^{\mathrm{a}}$ & $0,10^{\mathrm{C}}$ & $0,10^{\mathrm{C}}$ & $0,10^{\mathrm{C}}$ & $0,10^{\mathrm{C}}$ \\
\hline Suplemento vitamínico & $0,40^{b}$ & $0,40^{\mathrm{b}}$ & $0,40^{\mathrm{d}}$ & $0,40^{\mathrm{d}}$ & $0,40^{\mathrm{d}}$ & $0,40^{d}$ \\
\hline L-Lisina & 0,110 & 0,140 & 0,180 & 0,170 & 0,150 & 0,150 \\
\hline TOTAL & \multicolumn{6}{|c|}{100,00} \\
\hline \multicolumn{7}{|l|}{ Valores obtidos } \\
\hline E.D., $\mathrm{kcal} / \mathrm{kg}$ ração & 3.265 & 3.265 & 3.274 & 3.267 & 3.297 & 3.276 \\
\hline P.B., \% & 17,50 & 17,32 & 14,30 & 14,35 & 12,50 & 12,64 \\
\hline $\mathrm{Ca}, \%$ & 0,77 & 0,71 & 0,53 & 0,55 & 0,62 & 0,62 \\
\hline $\mathrm{P}, \%$ & 0,53 & 0,50 & 0,53 & 0,55 & 0,50 & 0,49 \\
\hline $\begin{array}{l}\text { FDN oferecido pelo feno, } \\
\qquad \%\end{array}$ & - & 8,00 & - & 8,00 & - & 8,00 \\
\hline
\end{tabular}

aSuprindo as seguintes quantidades por kg de ração: Fe 45 mg; Cu 7,5 mg; Mn 7,5 mg; Zn 65 g; 42 mg; Co 10 mg. bSuprindo as seguintes quantidades por kg de ração: vit. A 6500 UI; vit. $D_{3} 1500$ Ul; vit. E 15 UI; vit. K 2,8 mg; vit. B 1,5 mg; vit. B 4 mg; vit. B 1,5 mg; vit. B B $_{12} 18$ mcg; ác. nicotínico $20 \mathrm{mg}$; ác. fólico 0,55 mg; ác. pantotênico $15 \mathrm{mg}$; biotina $12 \mathrm{mg}$. 'Suprindo as seguintes quantidades por kg de ração: Fe 45 mg; Cu 7,5 mg; Mn 7,5 mg; Zn 65 g; I 42 mg; Co 10 mg. ' Suprindo as seguintes quantidades por kg de ração: vit. A 6500 UI; vit. D 1500 UI; vit. E 15 UI; vit. K 2,8 mg; vit. $B_{1} 1,5$ mg; vit. $B_{2} 4$ mg; vit. B 1,5 mg; vit. B 18 mcg; ác. nicotínico 20 mg; ác. fólico 0,55 mg; ác. pantotênico 15 mg; biotina 12 mg.

lignina ${ }^{24}$. De acordo com Schneeman ${ }^{20}$, o digesta percorrendo o trato gastrointestinal continua a manter a característica de "volume", fato que provavelmente promove distensão da parede destes órgãos e subseqüente aumento do peso de alguns dos órgãos digestivos (Tabela 2).
Ausência de alterações no peso de alguns órgãos (estômago cheio, intestino grosso, ceco vazio, colo cheio, colo vazio, fígado, vesícula biliar, baço, rins e pulmões) dos animais tanto da fase de creche como do crescimento-terminação, está de acordo com o registrado por outros pesquisado-res ${ }^{13,25,22}$. Pond et al. ${ }^{26} \mathrm{e}$ 
Tabela 2 - Pesos médios dos órgãos digestivos e não digestivos (expressos em percentual do peso vivo) de leitões em fase de creche, alimentados com rações contendo dois níveis de fibra em detergente neutro (FDN)

\begin{tabular}{|c|c|c|c|c|c|c|}
\hline \multirow{2}{*}{$\begin{array}{c}\text { Peso Órgãos, } \\
\text { \% PV }\end{array}$} & \multicolumn{2}{|c|}{ FDN (\%) } & \multirow[b]{2}{*}{ Média } & \multicolumn{3}{|c|}{ Análise de variância } \\
\hline & 0 & 8 & & $\mathrm{EPM}^{1}$ & $\mathrm{CV}^{2}$ & $P=F$ \\
\hline TGI total & 10,80 & 11,12 & 10,96 & 1,040 & 9,49 & 0,450 \\
\hline Estômago cheio & 1,02 & 1,11 & 1,07 & 0,167 & 15,67 & 0,185 \\
\hline Estômago vazio** & 0,76 & 0,91 & 0,83 & 0,082 & 9,794 & 0,0001 \\
\hline Intestino delgado & 5,39 & 4,97 & 5,18 & 0,619 & 11,95 & 0,108 \\
\hline Intestino grosso* & 3,42 & 3,91 & 3,66 & 0,595 & 16,25 & 0,045 \\
\hline Ceco cheio $* *$ & 0,45 & 0,76 & 0,60 & 0,170 & 28,24 & 0,0001 \\
\hline Ceco vazio & 0,21 & 0,22 & 0,22 & 0,041 & 18,90 & 0,849 \\
\hline Colo cheio & 2,97 & 3,16 & 3,06 & 0,532 & 17,35 & 0,381 \\
\hline Colo vazio & 1,67 & 1,61 & 1,64 & 0,268 & 16,38 & 0,589 \\
\hline Fígado & 2,40 & 2,27 & 2,34 & 0,321 & 13,73 & 0,295 \\
\hline Vesícula biliar & 0,08 & 0,07 & 0,07 & 0,028 & 39,82 & 0,407 \\
\hline Baço & 0,19 & 0,20 & 0,20 & 0,069 & 35,07 & 0,613 \\
\hline Rins & 0,45 & 0,41 & 0,43 & 0,068 & 15,72 & 0,106 \\
\hline Pulmões & 1,49 & 1,60 & 1,55 & 0,260 & 16,84 & 0,279 \\
\hline
\end{tabular}

Tabela 3 - Pesos médios dos órgãos digestivos e não digestivos (expressos em percentual do peso vivo) de suínos em fase final de terminação, alimentados com rações contendo dois níveis de fibra em detergente neutro (FDN)

\begin{tabular}{|c|c|c|c|c|c|c|}
\hline \multirow{2}{*}{$\begin{array}{c}\text { Peso Órgãos, } \\
\text { \% PV }\end{array}$} & \multicolumn{2}{|c|}{ FDN (\%) } & \multirow[b]{2}{*}{ Média } & \multicolumn{3}{|c|}{ Análise de variância } \\
\hline & 0 & 8 & & $\mathrm{EPM}^{1}$ & $\mathrm{CV}^{2}$ & $\mathrm{P}=\mathrm{F}$ \\
\hline TGI total ${ }^{*}$ & 7,28 & 7,99 & 7,64 & 0,719 & 11,10 & 0,050 \\
\hline Estômago cheio & 0,83 & 0,93 & 0,88 & 0,021 & 16,78 & 0,126 \\
\hline Estômago vazio** & 0,63 & 0,75 & 0,69 & 0,005 & 10,45 & 0,001 \\
\hline Intestino delgado & 2,27 & 2,74 & 2,61 & 0,170 & 15,86 & 0,128 \\
\hline Intestino grosso & 2,67 & 3,09 & 2,88 & 0,419 & 22,48 & 0,132 \\
\hline Ceco cheio & 0,50 & 0,55 & 0,53 & 0,038 & 37,14 & 0,557 \\
\hline Ceco vazio & 0,21 & 0,21 & 0,21 & 0,003 & 24,78 & 0,706 \\
\hline Colo cheio & 2,19 & 2,54 & 2,36 & 0,298 & 23,11 & 0,131 \\
\hline Colo vazio & 1,14 & 1,18 & 1,16 & 0,039 & 17,19 & 0,599 \\
\hline Fígado & 1,38 & 1,39 & 1,38 & 0,022 & 10,78 & 0,787 \\
\hline Vesícula biliar & 0,10 & 0,11 & 0,11 & 0,001 & 30,16 & 0,575 \\
\hline Baço & 0,19 & 0,17 & 0,18 & 0,001 & 16,47 & 0,071 \\
\hline Rins & 0,38 & 0,38 & 0,38 & 0,002 & 11,43 & 0,967 \\
\hline Pulmões & 1,16 & 1,04 & 1,10 & 0,047 & 19,87 & 0,204 \\
\hline Coração & 0,36 & 0,38 & 0,37 & 0,002 & 12,17 & 0,422 \\
\hline
\end{tabular}


Hale, Newton e Haydon ${ }^{27}$ não observaram efeito significati-vo da dieta fibrosa $(26 \%$ FDN) sobre o peso do estômago vazio, intestino delgado, ceco e colo, coração, pulmão, rins e fígado de suínos em fase de crescimento. Há que se destacar alguns fatores que podem ter interferido nos resultados: a qualidade da fibra empregada, se mais ou menos fermentescível; concentração de fibra na dieta; e padrão racial dos animais utilizados.

Já Kass, Van Soest e Pond ${ }^{25}$ ao empregarem teores de FDN de 31 e 43\% na ração de suínos em crescimento, o peso do estômago vazio apresentou-se significativamente menor em relação ao controle; entretanto, o intestino delgado, ceco e colo apresentaram-se mais pesados.

É importante ressaltar que a natureza morfológica do aumento do peso dos órgãos digestivos e não digestivos e seus respectivos significados biológicos, ainda não está completamente elucidado. A literatura registra vários estudos sobre o tema; entretanto, a quantidade e a diversidade dos materiais fibrosos empregados nas formulações para suínos tanto na fase de creche como na de terminação, dificultam a interpretação adequada dos resultados experimentais. Desta maneira, sugere-se a continuidade de estudos mais abrangentes enfocando rações contendo diferentes fontes e concentrações de fibra dietética e respostas do trato gastrointestinal.

\section{Conclusões}

O oferecimento contínuo de dieta contendo incremento de baixo nível de fibra em detergente neutro ( $8 \%$ FDN) na ração de suínos nas fases de creche e de crescimento-terminação promoveu alteração morfológica em relação ao peso de alguns órgãos digestivos, indicando adaptação orgânica dos animais ao componente fibra dietética. Esta adaptação possibilita uma estratégia alimentar na granja suinícola que diminui a competição por grãos com as aves e com a espécie humana.

\section{Agradecimentos}

Os autores agradecem o auxílio financeiro concedido pela Fundação de Amparo à Pesquisa do Estado de São Paulo (FAPESP).

\section{Effects of increasing neutral detergent fiber in swine diets on the morphology of digestive and non-digestive organs}

\begin{abstract}
This work was targeted to evaluate the effects of including 0 or $8 \%$ of neutral detergent fiber from grass hay on the morphology of digestive and non-digestive organs of swine receiving starting or growingfinishing diets. It was employed cross-bred animals fed isoproteic and isoenergetic ad libitum rations in a completely randomized experimental design. At the end of each period, animals were slaughtered and eviscerated. It was detected that the fibrous ration increased the weight of empty stomach, large intestine and filled cecum (as a percentage of live weight) of starting animals. In the growing-finishing animals fibrous ration increased the weights of filled gastrointestinal tract and empty stomach. Higher weights of some digestive organs suggest a possible morphological adaptation to high fiber diets.
\end{abstract}

Keywords:

Dietary fiber.
Digestive tract. Hay. 


\section{Referências}

1 POLLMANN, D. S.; DANIELSON, D. M; PEO JR., E. R. Value of high fiber diets for gravid swine. Journal of Animal Science, v. 48, p. 1385-1393, 1979.

2 BROUNS, F.; EDWARDS, S. A.; ENGLISH, P. R. Effect of dietary fibre and feeding system on activity and behaviour of housed gilts. Applied Animal Behaviour Science, v. 39, p. 215-223, 1994.

3 RAMONET, Y.; MEUNIER-SALAÜN, M. C.; DOURMAD, J. Y. High-fiber diets in pregnant sows: digestive utilization and effects on the behavior of the animals. Journal of Animal Science, v. 77, p. 591-599, 1999.

4 ROBERT, S.; MATTE, J. J.; FARMER, C.; GIRARD, C. L.; MARTINEAU, G. P. High-fiber diets for sows: effects on stereotypes and adjuntive drinking. Applied Animal Behaviour Science, v. 37, p. 297-309, 1993.

5 BECKER, B. G. Bem-estar dos suínos. In: SIMPÓSIO NACIONAL DE SUINOCULTURA, 2., 2001, Foz do Iguaçu. Anais... p. 95-102.

6 LUNA, A. M. Bienestar de los cerdos: las normas europeas y una propuesta de bienestar razonable. In: CONGRESSO LATINO AMERICANO DE SUINOCULTURA, 1., 2002, Foz do Iguaçu. Anais... p. 22-43.

7 VAREL, V. H.; POND, W. G.; YEN, J. T. Influence of dietary fiber on performance and large intestinal microflora of growing swine. Swine Research Progress Report, n. 1, p. 51-52, 1983.

8 BRUNSGAARD, G. Effects of cereal type and feed particle size on morphological characteristics, epithelial cell proliferation, and lectin binding patterns in the large intestine of pigs. Journal of Animal Science, v. 76, p. 2787-2798, 1998.

9 SAKATA, T. Chemical and physical trophic effects of dietary fiber on the intestine of monogastric animals. Pig News Information, v. 12, p. 165, 1991. Abstracts.

10 VON ENGEELHARDT, W.; RÖNAU, K.; RECHKEMMER, G.; SAKATA, T. Absorption of shortchain fatty acid and their role in the hindgut of monogastric animals. Animal Feed Science and Technology, v. 23, p. 43-53, 1989.

11 CASSIDY, M.M. et al. Effect of cronic intake of dietary fibers on the ultrastructural topography of rat jejunum and colon: a scanning electron microscopy study. Animal Journal Clinical Nutrition, v. 34, p. 218-227, 1981.
12 JIN, L. et al. Effects of dietary fiber on intestinal growth, cell proliferation, and morphology in growing pigs. Journal of Animal Science, v. 72, p. 2270-2278, 1994.

13 GOMES, J. D. F. Efeitos do incremento da fibra em detergente neutro, sobre parâmetros de desempenho, de digestibilidade dos componentes dietéticos e da morfologia intestinal de marrãs. 1996. 110 f. Tese (Doutorado) - Faculdade de Medicina Veterinária e Zootecnia, Universidade Estadual Paulista, Botucatu.

14 PENZ JÚNIOR, A. M. Alimentação à vontade para porcas em gestação. In: SEMINÁRIO NACIONAL DE SUINOCULTURA, 2., 2001. Foz do Iguaçu. Anais... p. 29-52.

15 NATIONAL RESEARCH COUNCIL - NRC. Nutrient requirements of pigs. 10. ed. Washington: National Academy of Sciences, 1998. 189 p.

16 GOERING, H. K.; VAN SOEST, P. J. Forage fiber analysis: apparatus, reagents, procedures and some applications. Washington: Agricultural Research Service, 1970. 76 p.

17 ASSOCIATION OF OFFICIAL ANALYTICAL CHEMISTS - AOAC. Official methods of analysis. Washington: Association of Analytical Chemistry, 1980. $1015 \mathrm{p}$.

18 SAS INSTITUTE. SAS user's guide: statistics. Cary, NC: SAS Institute, 1992.

19 HANSEN, I. K.; KNUDSEN, E. B.; EGGUM, B. O. Gastrointestinal implications in the rat of wheat bran, oat bran and pea fiber. The British Journal of Nutrition, v. 68 , p. $451-462,1992$.

20 SCHNEEMAN, B. O. Fiber, inulin and oligofrutose: similarities and differences. The Journal of Nutrition, v. 129, p. 1424S-1427S, 1999.

21 PEKAS, J. C.; YEN, J. T.; POND, W. G. Gastrointestinal carcass and performance traits of obese versus lean genotype swine: effect of dietary fiber. Nutrition Reports International, v. 27, p. 259-270, 1983.

22 POND, W. G.; JUNG, H. G.; VAREL, V. H. Effect of dietary fiber on young adult genetically lean, obese and contemporary pigs: body weight, carcass measurements, organ weight and digesta content. Journal of Animal Science, v. 66, p. 699-706, 1988.

$23 \mathrm{HUO}, \mathrm{G}$. C. Utilization of fibrous materials by the indigenous breed of pigs (Northeast mini pig). 2. Morphological changes in the digestive tract and digesta in colon. Pig News Information, v. 15, p. 382, 1994. 
Abstracts.

24 FUKUSHIMA, R. S.; DEHORITY, B. A. Feasibility of using lignin isolated from forages by solubilization in acetyl bromide as a standard for lignin analyses. Journal of Animal Science, v. 78, p. 3135-3143, 2000.

25 KASS, M. L.; VAN SOEST, P. J.; POND, W. G. Utilization of dietary fiber from alfalfa by growing swine. II. Volatile fatty acid concentrations in and disappearance from the gastrointestinal tract. Journal of Animal Science, v. 50, p. 192-197, 1980.

26 POND, W. G. Dietary alfalfa meal for genetically obese and lean growing pigs, effect on body weight gain and gastrointestinal tract measurement and blood metabolites. Journal of Animal Science, v. 51, p. 367373, 1981.

27 HALE, O. M.; NEWTON, G. L.; HAYDON, K. D. Effect of diet and exercise on performance, carcass traits and plasma components of growing, finishing barrows. Journal of Animal Science, v. 62, p. 665-671, 1986.

28 POND, W. G.; VAREL, V. H.; DICKSON, J. S.; HASCHEK, W. M. Comparative response of swine and rats to high-fiber or high-protein diets. Journal of Animal Science, v. 67, p. 716-723, 1989. 